\title{
Mergers and managers: what's needed for both to work? Reflections on a merger of two higher education libraries in KwaZulu-Natal
}

\author{
NJ Muller' \\ Durban University of Technology Library, P O Box I334, Durban 4000 \\ muller@dut.ac.za
}

\begin{abstract}
Received: $15^{\text {th }}$ April 2006
Accepted: $6^{\text {th }}$ September 2006

Mergers are not an occasion; they are a process, and it is important to understand how such processes unfold and the concomitant stress factors that are brought about by the change. During a merger, staff can feel overstretched and overburdened. A logical output of this is that neglect of normal business operations occurs. There are various management strategies recommended in the literature which can be put into place to ensure that such overload and neglect does not lead to failure of the merger. This paper briefly outlines the various cycles that mergers take, as well as highlighting the stresses that mergers place on employees. It focuses more particularly on what skills and strategies are required by managers to ensure that such employee stress is diminished and that employees feel competent, able and willing to handle the operational requirements of the merger appropriately. The paper draws on experiences of the Durban Institute of Technology library during its merger process.
\end{abstract}

Keywords: Mergers - Higher education; Library mergers: Change management: Mergers - employee stress: Durban University of Technology (DUT)

\section{Introduction}

The South African Higher Education landscape, after the democratic elections of 1994, saw various strategies being employed to effect significant change in that sector, with the rationale that the restructured landscape would be:

socially just and equitable in its distribution of resources and opportunities, ... meet the requirements of longterm sustainability and ... enhance the productivity of the system through effectively and efficiently meeting the teaching, skills development and research needs of the country (Macozoma 2002:I).

This would lay the foundation for a higher education system that is consistent with the vision, values and principles of democracy and which would contribute to social and economic development. One mechanism of effecting such change was the merging of various higher education (HE) institutions. The first HE merger took effect in April 2002 between the M L Sultan Technikon and Technikon Natal, KwaZulu-Natal, to form the Durban Institute of Technology (DUT). These institutions each had established libraries, and the two library directors were jointly responsible for ensuring a single, unified and cohesive library system, operating across six sites of teaching delivery in Durban and Pietermartizburg.

This paper serves to highlight some of the particular stresses brought about by merger, how these affect employees and the role that managers can play in helping employees through the change. Reflections on the experience of the Durban Institute of Technology library will also be made.

\section{The merger process and cycle}

Mergers are not an occasion; they are a process, and it is important to understand how such change processes unfold and the stress factors that are brought about by the change. Mergers are also particularly complex in terms of change management.

The human emotional and behavioural issues are but one element of the three essential elements required for successful change, the others being strategy and execution. In a merger the sensitivity to these various elements required exceeds that of other change situations. Duck (200I) indicates that change management in merger situations is a quantum leap away from managing a new production project or changing systems within an organisation. It is thus important to understand that in mergers, scale and complexity are the dominant factors while time may not be a significant concern.

Clarke (1994), Jerome (1994), Strickland (1998), Devine and Hirsh (1998), Duck (200I), and Coffey, Garrow and Holbeche (2002) all maintain that change occurs in various phases, which can be mapped on a change continuum. There are particular dynamics which occur within each phase, and particular interventions which may be needed to move employees on to the next stage or phase. When an organisation is in the midst of change, different departments and subgroups can typically be in different phases at any given time. Individuals also experience change differently from one

I. Nicky Muller is Deputy Director, Durban University of Technology Library, Durban, South Africa. 
another. Furthermore, individuals and subgroups do not always progress from one phase to the next in an orderly sequence and may sometimes get stuck in a particular phase. This was true of the DUT experience. While the library progressed significantly with the integration of its various systems, policies and procedures, many other departments remained tied to their previous ('normal') mode of operation.

Managers need to understand the various phases of change to be able to prepare for what is typically expected in each phase and the characteristic responses from staff.

Devine and Hirsh (1998) identify four stages in change, namely:

Run-up $\rightarrow$ Transitional Change $\rightarrow$ Integration $\rightarrow$ Closure

They list the key characteristics and responses by employees of each of these phases as follows:

a) run-up: intense pressure, uncertainty, strong anxiety/paranoia, loss of direction and focus

b) immediate transitional change: work pressure, fear and anxiety re job losses, heightened responses, preoccupation with new appointments

c) integrative stage: sense of pressure, preoccupation with and working through differences, cultural sensitivity

d) closure: relief and achievement, letting go of the past. If there is no closure, the possibility exists for lingering resentment, unwillingness to let go, introspection and uncertainty (Devine and Hirsh 200 I: 17-19).

Pritchett, Robinson and Clarkson (1997) advocate five stages in a merger implementation, namely:

Envision $\rightarrow$ Assess $\rightarrow$ Deploy $\rightarrow$ Manage $\rightarrow$ Close

The business of each of these stages is identified as follows:

a) envision: laying the groundwork for successful integration

b) assess: evaluating current operations and recommending changes based on integration requirements

c) deploy: deployment of resources and improvising where needed

d) manage: accounting for progress, resource utilisation and so on

e) close: handover to appropriate operating groups and qualitative assessment

Duck (200I) also identifies five stages, namely:

Stagnation $\rightarrow$ Preparation $\rightarrow$ Implementation $\rightarrow$ Determination $\rightarrow$ Fruition

Duck's exposition of each of these stages is particularly useful, enumerating the key activities and characteristics, as follows:

a) The stagnation period is characterised by poor strategy, lack of leadership, too few resources, and/or outdated technology.

b) The preparation stage starts when the decision to change is made. During this stage there is a considerable amount of operational work to be done. The key characteristic displayed by employees is one of heightened emotions: they are anxious, jittery, hopeful, threatened, betrayed, excited, jockeying for position and/or defending their turf. If this preparation phase goes on for too long, it starts unravelling and could become a new form of stagnation.

c) The implementation stage is characterised by people hedging bets and by a sense of unreality. Implementation is about defining and managing the implementation of new organisational structures, job definitions, and processes and interfaces.

d) The determination phase is a time for reinforcement and is the phase where the fate of the change process is determined. The results of all the cumulative efforts should be evident in this phase, but Duck states that fatigue sets in. It is tiring, for managers and employees, to be continually rethinking one's daily work as well as changing ways of operating. This phase is where working out how to make the new vision a reality happens.

e) Fruition is the time to acknowledge that hard work is paying off, to recognise achievements and to share rewards. The two major opportunities to be grasped during this phase, according to Duck, are to cement trust and unity; and to embed the capabilities and attitudes that have produced successes (Duck 200I:254). It is 
important that celebration and reward need to be managed as carefully and thoughtfully as any other aspect of change, as there is always the danger that celebration may turn into self-congratulations and complacency (Duck 200I:256). Duck suggests capturing the learning to help the workforce internalise their experiences so that what has been learned and achieved during change is not lost.

In the envisioning or preparation stages, it is critical to prepare staff for the change, and to understand and accept the reason for the change. Garrow, in Jayaram (2003) indicates that in the DUT library merger, 'Although the combination of financial and human resources could result in a bigger, better, more thriving institution with a reduction in duplication, the decision to press ahead with merger nevertheless came as a shock to many staff who believed it would never happen.' Jayaram expresses the opinion that '.. if staff were adequately prepared for the change, it might have been a different scenario' and points to the lack of adequate change management preparation within the institution (Jayaram 2003:89).

Effective managers are those who have been prepared for the change process and who understand the effects that each phase can have on employees. In the DIT experience, little assistance was given to managers in understanding their roles in a changing environment, as well as supporting their employees. There are particular challenges for managers that run throughout the change process, some of which will be enumerated in the next section.

\section{Some human emotional and behavioural challenges faced during the merger}

For the purposes of this paper, some of the emotional and behavioural challenges will be examined in terms of what managers will be faced with and how they can prepare themselves. If a manager wins over her employees, she can will them to move and to vote with their feet in supporting change (Duck 200I).

\section{Personal stress}

For most people change hurts. It sometimes involves loss - of the past, of routine, comfort, relationships, security, and identity. It often involves a change in knowledge - of facts and of understanding. It can address emotions - individuals have fears and attachments. When people experience a high level of uncertainty, their response is to move to protect themselves. Consequently, coping behaviours tend to be self oriented and dysfunctional as far as the organisational good is concerned. Studies agree that usually during this time management finds it hard to predict how employees will respond as emotion and obscure motives are the natural reaction, not logic or rational thought. For example, Coffey, Garrow and Holbeche (2002) list the negative effects of change on employee behaviour as a deterioration in communication, poor productivity, deterioration in team play and an increase in parochialism, increased power struggles which disrupt work, decreased levels of commitment, and a tendency of employees to 'bail out'. This was experienced in the DIT library environment where absenteeism (sick leave) increased by $26.6 \%$ in the first year of merger (Muller 2003: I43). Devine and Hirsh (1998) further indicate that staff need to know that their own redundancies, relocations or job changes are going to be handled clearly, sympathetically and efficiently. Staff who are distracted by unnecessary confusion about plans for their own jobs cannot contribute to the existing business or to merger processes. If key appointments are seen as being politically driven or favouring one side, it can result in major loss of morale and confidence. Jayaram (2003:89) comments on the DUT environment: 'Key dependencies had not been worked out. HR issues remain a source of serious concern for staff at DIT[DUT] libraries. Although staff have moved into the new institution (in terms of the labour laws) with the same terms and conditions of service that they enjoyed at their former institutions, subsequent changes in employment conditions, and fears over job losses are an inescapable reality for DIT'.

Clarke (1994:109) lists some of the individual's resistance to change as being the following:
a) loss of control
b) questioning necessity of change
c) uncertainty and ambiguity
d) surprises being sprung
e) loss of face to the individual
f) questioning of own competence and coping ability
g) fear of more work.

Clarke indicates that these resistors stem from psychological emotions such as fear of the unknown, lack of information, threats to status, threats to established skills, fear of failure, reluctance to let go, lack of perceived benefits, threats to powerbase, low-trust organisational climate, fear of looking stupid, feeling vulnerable and exposed, threat to self esteem, loss of control of one's own destiny, loss of team relationships, high anxiety and stress (Clarke 1994:109).

Many people resist change, particularly if they do not understand why the change is being introduced. Resistance to change can hinder adaptation and progress. Change of the magnitude of a merger usually has a negative impact on employees, at least initially. Employees usually have no say in the matter and so this change is not of their own making and is thus feared. Because there is no personal ownership of the decision, managers have to work hard to ensure some buy- 
in to the change. Robbins indicates that resistance to change is not necessarily evident: it can be overt, implicit, and immediate or deferred (Robbins 1991:640). There is a greater challenge for managers to respond to implicit or deferred resistance as these efforts are usually more subtle, including loss of motivation and increased absenteeism. According to him, individual resistors to change reside in habit, in security, in economic factors (concern about reduced income), in fear of the unknown (ambiguity and uncertainty in place of the known) and finally in selective information processing (keeping perceptions intact) (Robbins 1991:640-64I).

Devine (1997) is supported by other authors ( eg. Duck 200I, Coffey, Garrow and Holbeche 2002, KPMG 2002) who observe that many employees go through a cycle of emotions even when they are not directly experiencing change, when they see their former institution or organisation disappearing, and when they see their immediate work environment change. During a merger employees will feel little affiliation with the new emerging entity, and will not have the normal channels of communication open to them. Snowden (2002) suggests that it can take up to three years for an individual's network of personal linkages to be re-established and for some form of security and sense of belonging to settle in.

Clarke (1994) indicates that a typical reaction to significant change occurs in four stages, namely shock, then defensive treatment, followed by acknowledgement and then finally adaptation. Marks, in Coffey, Garrow and Holbeche (2002), also shows that employees in mergers often pass through four distinct stages, namely disbelief and denial, anger, emotional bargaining ending in depression, and finally, acceptance. These are similar to the stages identified by Elizabeth Kubler-Ross in her bereavement curve analysis and shown in the diagram below. Devine and Hirsh (2002) state that many organisations find the Kubler-Ross transition curve a helpful aid to understanding how people and organisations work through any kind of difficult change. This transition curve encapsulates the four stages described above.

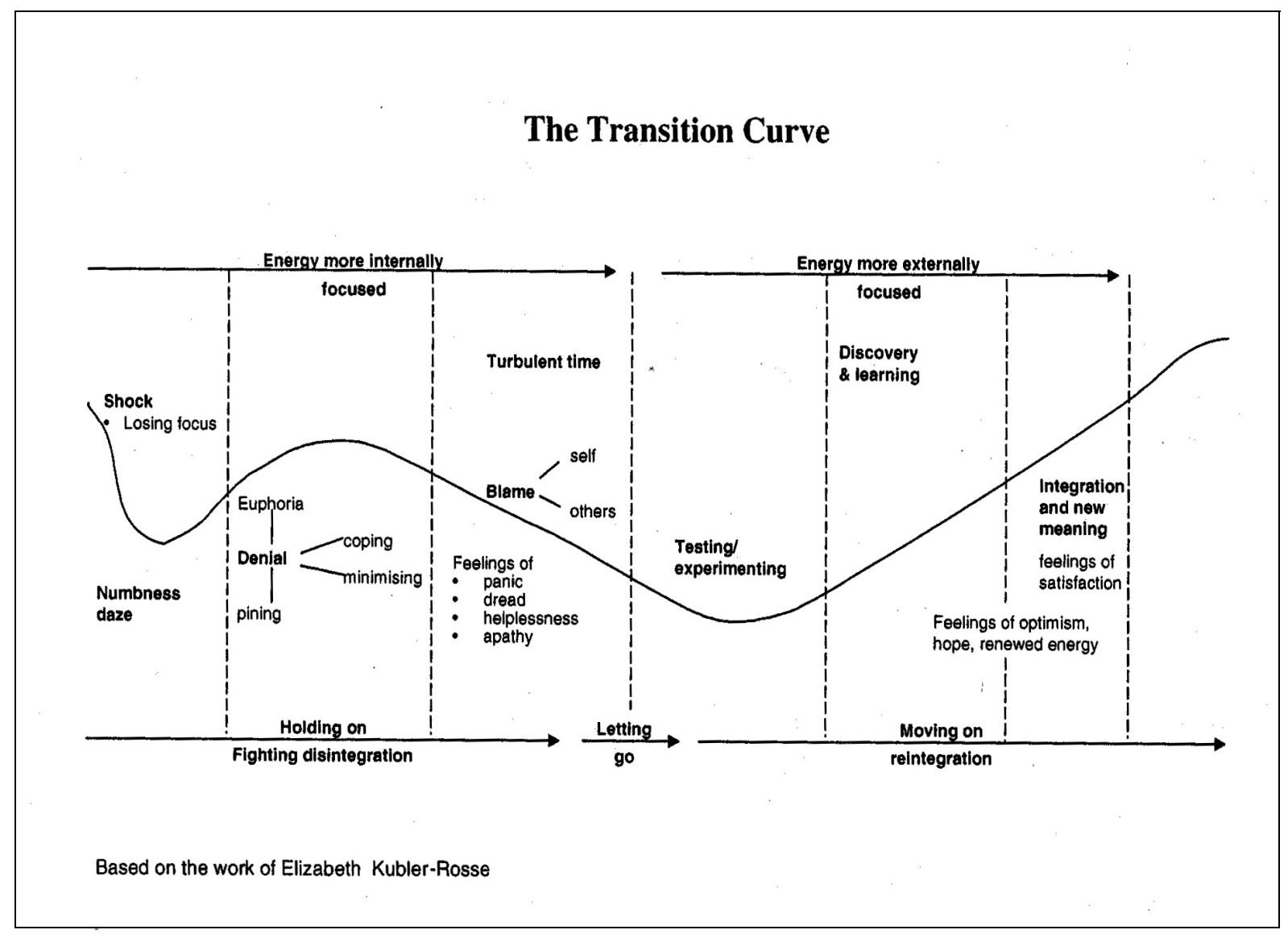

Figure I The transition curve. Source: Devine and Hirsh 1998:13

If managers understand how the different emotional waves affect different parts of the change process, they should be able to find appropriate strategies to manage these. Devine (1997) warns that even if one is positive about a merger, this does not mean that there will not be a period of 'grieving'. The challenge is to work on perceptions of change so that employees see more of the positives and less of the negatives. The starting point for change management is helping everyone to understand why change is required. 
Job security and uncertainty

Uncertainty, a common element in major change, can be dangerous for a merger. The following elements increase uncertainty:

- Lack of communication. Some attempt must be made to address the 'me factors' early if staff morale is not to be damaged unduly

- Degree and speed of real integration

- Process of deployment of staff. Deployment is usually damaged by two main factors, namely politics and lack of information. The process must be seen to be equitable and as transparent as possible (Coffey, Garrow and Holbeche 2002:39).

In the DUT library experience, Garrow identified job security as being a resistor to staff working well together. She indicated that staff were challenged with having to find common ground, to understand the new issues and dynamics, and to develop working relationships with new colleagues who were likely to be potential future rivals for jobs (Garrow 2003:20). Job security was also threatened with regard to career progression, as there would now be more contenders for the same job, and possibly against individuals who had more experience, particular skills or a higher qualification. Furthermore, staff were sceptical of messages received from institutional management about job security: 'The only thing we get from the higher institute which has been passed down is "don't fear job losses at the moment" and of course nobody trusts that because in any merger you have job losses and that causes more incredulity because you know it will be there at some time and its pulling the wool over people's eyes' (Garrow 2003:10). Job security is a significant staff concern, and the process of appointments must be seen to be fair (Devine 1998, Coffey, Garrow and Holbeche 2002). Garrow (2003) found that staff had fears of job loss through retrenchment, and that these fears pertained to what criteria might be used for determining appointments. This affected productivity considerably.

\section{Communication}

Communication is a vital factor in any change process. Coffey, Garrow and Holbeche (2002) go so far as to say that communication is often hailed as the most important factor in a merger's success. Communication is not just about passing on information. It also has a vital role in reducing anxiety, managing expectations, demonstrating concern, promoting integration, building new networks, building trust and commitment, encouraging involvement through feedback and two way communication, and prompting behaviour changes or 'walking the talk' (Coffey, Garrow and Holbeche 2002:166). They say that when staff are in a negative mode (or when the climate is bad), any 'spin' on communication is likely to generate cynicism. Employees read into heightened tensions. In this sense every management action is part of the communication process. In order to build credibility and trust, communication in the form of words, actions and outcomes must be aligned.

Duck (200I) indicates that in change the informal networks of communication are often disrupted or destroyed and that it takes longer for people to do their work and to figure out who to talk to as networks need to be rebuilt. These gaps create opportunity for uncertainty of interpretation. This view is supported by Snowden (2002) and is aligned to the disruption of the psychological contract put forward by Coffey, Garrow and Holbeche (2002). These authors indicate that during high risk/low trust situations such as the various stages of a merger, there are some basic rules which can be applied to communication. They describe the principles of Dr Vincent Covello, Director of the Centre for Risk Communication in the United Kingdom, which are applicable to a merger situation where emotions are running high. He puts forward the following theoretical constructs:

I. Trust determination theory: Trust can only be established by the recipient of the message who wants to be cared for before caring about what you know. Trust is built up over a long period of time but can be destroyed very quickly. Trust factors include empathy, competence, honesty, and commitment.

2. Mental noise theory: Upset people have difficulty hearing and processing information. Information thus needs to be repeated frequently and there should be a limited number of messages that have to be absorbed.

3. Negative dominance theory: Upset people tend to think negatively. It is thus advisable to avoid negative words.

4. Risk perception theory: What is perceived is real in its consequences. Perceptions of risk are influenced by existing levels of trust, perceived benefits, level of control and perceived fairness.

(Coffey, Garrow and Holbeche 2002).

From the studies it is clear that emphasis is required on communication that is simple, consistent and that is repeated. Managers need to understand that when individuals are under threat, normal communication processing is disturbed (Robbins 199I, Senior 1997, Duck 200I and others). In the DUT library situation it was evident on the whole that when communication occurred in a clear, thought out manner, its reception was generally favourable. Muller (2003:172) indicates that 'Unfortunately ... it appears that such quality communication happened sporadically rather than 
consistently. There were also instances when library managers were challenged as to their transparency, because clear communication had not happened.' Information vacuums should not be allowed to occur in an ambiguous environment. Employees need to hear more from their managers. In the DUT library experience, a clear communications strategy that flowed in all directions was lacking, as was an understanding of Covello's four theories outlined above. Managers thus found themselves communicating in various ways and repeating messages, but being exasperated when staff complained that there was insufficient communication. It is recommended that communication 'watchers' should be identified who can caution when communication is inadequate, not being transferred or understood. What became evident in the DUT experience was that in times of high stress, face-to-face communication needed to be increased (this was not always the case). Duck (200I) also recommends that communication should not only focus on decisions, but should also discuss processes involved, who's involved, ideas that have been used or discarded, anticipated timelines, and so on.

\section{Managers in merger}

The people and so-called 'soft' issues are what can make the difference between success and failure. Coffey, Garrow and Holbeche (2002) state that managers who are under severe stress themselves may not be able to deal with such issues. A significant challenge is that employees' concerns rise rather than fall when managers are unable to handle implementation issues because of their own stress levels.

Devine (1997) indicates that staff will look to their line managers for consolation and encouragement, yet in her research she found that line managers can often be the hidden casualties of mergers. Mergers can send a flurry of conflicting priorities to line managers. Line managers have to continue overseeing all normal operational activities. With systems in a state of flux, the normal decision making processes are disrupted; line managers may possibly not be clear about what decisions they have authority to make and what should be referred upwards. A comment made to her in the course of her research was that 'Line managers often don't know the answers and are not formulating policy. They can become very disempowered to resolve employee issues as they often have to refer up the line matters they would have resolved themselves in more stable times' (Devine 1997:13). Informal networks for getting conflicting priorities resolved are also likely to have broken down owing to the change which exacerbates quick decision making and problem solving. Many authors stress the need for clear guidance of line managers in a time of turbulence. Such assistance can be in the form of short term advice on limits of discretion and by ensuring that temporary policies exist (Duck 200I). The DUT library merger evidenced such problems, with line managers taking considerable 'flak' and frustration from staff, without always having a clear understanding of procedures and lines of authority in an interim state.

During the initial phases of a merger there is a double workload: managers are not only leading a complex change process but are also running the core business. Devine and Hirsh (1998) state that in their experience the workload in a merger takes companies by surprise, even when they are experienced at managing their own operations. It is thus advisable to spread the workload and to ensure that there are enough competent managers to run the existing operations without also having to implement the merger.

Robbins (199I) states that under normal conditions the typical skills required of a manager include technical skills (the ability to apply specialised knowledge or expertise), human skills (the ability to work with, understand, and motivate other people, both individually and in groups) and conceptual skills (the mental ability to analyse and diagnose complex situations). Devine and Hirsh (1998) state that mergers create particular new challenges for managers and that skills need to be developed to handle larger and more complex roles. When managers need additional skills development to cope with these new complexities, it is at a time when they are too busy to invest in their own development (Devine and Hirsh 1998:39). A skill that they identify for managing mergers which was not found elsewhere in the literature is the ability to identify and retain key systems understanding as well as unique business and technical know-how until one is sure that this is not needed (Devine and Hirsh 1998:4I). Another skill they identify is the ability to build new teams. To support their argument they state that it is in the functional teams that the new organisation really takes shape (a premise concurred with earlier in this chapter). They differentiate the role of senior managers as being to remain in touch with this process of team building and to encourage some types of outcome and to discourage others.

In the DIT experience, the management team was composed of two directors of the former institutional libraries, one deputy director and a number of individuals who had been in acting positions. Once placement of staff was finalised, the management team comprised six individuals with varying levels of managerial experience. With increased workloads, managers found themselves in meeting after meeting. This resulted in a general feeling that managers were not accessible and not visible. 'Even with both Directors working side by side, the management workload increased dramatically so that maintaining the close day-to-day relationships with staff was difficult and they missed the attention' (Garrow 2003:46). Muller (2003:154) relates some comments made by library staff eighteen months into merger, supporting the sense that management was not sufficiently visible:

SA JnI Libs \& Info Sci 2006, 72(3) 
'management never around when needed'

'absent leadership'

'management too remote'

'management not fully exposed to staff especially junior staff'

Duck (200I) warns that during integration it is easy for managers to feel overwhelmed. Managers might have to use action to gain understanding and commitment rather than starting with the base of understanding and expecting that it will lead to a willingness to act. This was something that could have been taken note of in the DIT library situation: too often managers, out of a concern for the emotional well-being of their employees, hoped for the latter response rather than using action and galvanising a response.

\section{Strategies for managing merger}

From the foregoing discussion we have seen that a significant body of authors state that in any change process people issues are of paramount importance. If managers handle these people issues well, the new organisation can emerge with a stronger set of capabilities and a more robust attitude towards change. If managers fail to resolve people issues, the new business may well be held back by in-fighting at the top and confusion and low morale at the bottom (Devine and Hirsch 1998:3). The merger experience shapes the climate and culture of the emerging organisation. It is thus essential to take positive steps to ensure that the 'soft' issues of culture, values, behaviours and working styles help rather than hinder the change. Duck (200I) indicates that no organisation can change until the individuals within it change. They have to think and act differently or nothing will be different. For change to be real and long lasting, it has to take place deeply and completely - emotionally, intellectually and operationally.

To successfully manage change, leaders must manage people's expectations, energy and experience. Sometimes problems are symptomatic of deeper underlying emotional problems. Examples of such problems could be an inability to agree with new goals and not supporting them, or behaviour is inconsistent with the new business model, people refuse to work together, the original vision is questioned, the leaders' credibility is shaky, or early successes seem to evaporate. Duck indicates that these emotional problems could be viewed as retroactive resistance. She continues to reinforce the message that it is not uncommon to balk at 'inhabiting the new world' (Duck 2001:199).

The chance of the failure of a change process is increased if the challenges that people will encounter at the onset of change are not planned for and addressed. Participation by employees in the change process needs to commence as early as possible to ensure that solutions are fully owned by the people who will be affected, and to provide a solid platform for integration. Successful long term integration is dependent not only on understanding business or process issues but also on understanding the human issues.

Communication has been identified as a critical factor in the success of a merger. Information is the oxygen of the organisation. Stopping the flow temporarily or prematurely is dangerous The role of line managers in the communication cycle is extremely important. Particular skills and training may be needed at such a sensitive time, even for those line managers who under normal circumstances have a good rapport with their staff, and in particular, in communicating information to them. In the absence of any communication from the leaders, employees rely on other sources such as the media and the grapevine to arrive at their own conclusions.

Coffey, Garrow and Holbeche (2002) list the following useful guidelines for communicating with groups, and see these as particularly useful for line managers who often have to be the conduit for information:

- How will you make sure you are as well prepared as possible to deliver the message?

- Are you sure you are clear about the information you are presenting?

- Have you worked through how you feel yourself about the information you are presenting?

- How will you help yourself to own the message (over which you may have had little input or influence?)

- How will you help staff feel positive about the message (especially if you don't personally agree with it)

- What will you do to help staff to understand the content of the message and to move forward?

- Do you know whether the message is 'good' or 'bad' news for your staff?

- Be prepared to repeat key messages

- Be prepared to handle negative feelings after each major communication round

- Be honest and open at all times about the extent of your own knowledge

(Coffey, Garrow and Holbeche 2002: I79).

Duck (200I) also cautions that leaders may start to tire of the core change messages. It takes a long time, even in a stable climate, for the message to be heard and understood. She explains that usually leaders are not in close contact; they only see each other in meetings and seldom compare notes on organisational dynamics. Conflicting messages and uncoordinated efforts then continue and become more extreme over time. There is thus a tendency to make inaccurate 
assumptions because they do not have enough vertical contact with others and enough time to stay in touch, and thus confusion spreads.

In a time of disruption, communication is more essential than ever. Structures are different and modes and mechanisms of communication may have changed. KPMG (2002) stress that in times of extreme change, more than $55 \%$ of communication should be face to face. Communication is thus a considerable challenge for managers who may already be feeling swamped by the demands of their workload.

Many authors suggest mechanisms for dealing with organisational cultural integration, but Coffey, Garrow and Holbeche (2002) specifically recommend a cultural due diligence prior to merger activity. Due diligence is the process of getting to know as much as possible about the new partner, and it usually covers aspects such as financial data, operational, technical, human resources, legal and insurance aspects as well as an environmental due diligence. In their research they found that little attention, if any, is given to cultural issues. They suggest that the following issues should be investigated as part of the due diligence process:

- management styles and compatibility

- hierarchical relationships and balance of power

- decision-making styles

- acceptance of accountability

- how people are motivated

- working styles, e.g. teamwork, project oriented, directive

- role clarity and standards of performance

- customer service orientation

- employee views on management effectiveness

- investment in training and development and attitudes to learning and adaptability

- skills areas of weakness and strength

- flexibility and willingness to change

(Coffey, Garrow and Holbeche 2002:91)

The role that managers play in living the desired behaviours and building the desired culture explicitly, is another common issue identified by various authors. Coffey, Garrow and Holbeche (2002) indicate that employees will look to their leaders for a clear vision of the future of the organisation. In-fighting and dissension at senior levels can be particularly damaging as it works down throughout the organisation as divisive behaviour which is then embedded in the new culture. The damage that this does throughout the organisation, according to their research, is untold and immeasurable. They further state that the quality of management and the management style is important in setting the new cultural tone. Managers should demonstrate the values of the new organisation, as well as building commitment and understanding, minimising political behaviour, and translating the organisational objectives into individual performance targets. Amongst other things, these actions help to focus teams on maintaining their performance.

Duck (200I) indicates that one of management's prime activities should be to ensure alignment around strategy and vision; furthermore a 'healthy dissatisfaction with the status quo and a genuine appetite for change must be generated within the workforce; appropriate expectations of what will happen and what can be accomplished must be set' (Duck 2001:93). In terms of alignment of the management team, she says that

Employees are very skilful at assessing each executive's strength of commitment as well as the amount of alignment within a group. If they sense wavering commitment or a lack of solidarity, they take it as an invitation to mischief. Individuals and subgroups will choose sides and align themselves with an executive they like and trust, or with the one they believe will win in the end (Duck 200 I:95).

\section{Some further insights from the DIT library merger}

Communication at all levels was problematic, both in terms of channels used and in terms of language and expression. A case study of the library merger was undertaken by Valerie Garrow of the Coffey Research Institute in the United Kingdom, and some of her findings relating to communication included:

- staff indicated the degree of stress experienced because of having to be particularly careful about what they said and how they said it

- concerns that open debate was not appreciated

- perceptions that the new merger structures made communication more difficult and complex

- not enough direct communication (Garrow 2003)

These are supported by comments made from staff at various opportunities (General Library staff meetings, etc.)

- lack of communication from staff to management

SA Jnl Libs \& Info Sci 2006, 72(3) 
- concerns of a strong grapevine at work in the absence of formal communication

- concerns that management 'don't have ears to the ground' and were not visible (Muller 2003)

Organisational culture issues are frequently cited as producing tension in change situations, and particularly in mergers (Robbins 199I, Senior 1997, Duck 200I). Garrow indicates that in the MLST/TN environment 'the cultural map is extremely complex' (Garrow 2003:13). The author has highlighted some of the complexities of building a new cultural map, identified from Garrow's study.

- staff were aware of losses of familiarity and the way in which things were done previously

- concerns that the new environment or new culture might not be what was hoped for

- the management styles of the two library directors were seen by staff as symbols of the organisational culture and there was concern of the impact that these different management styles might have on the libraries

- concerns about losing their input into making decisions, linking this directly with the concern about the management styles

- integration was largely focused on operational issues

- there was inadequate attention to the cultural and emotional issues and to gaining employee commitment to the process

- concerns that the superficial politeness that existed could give rise to a particular culture of corridor or 'after meetings' (Garrow describes this as a shadow world of dissent)

Could the interim library management have done things differently? It is the author's belief that the interim library management should have played a firmer, more active role in handling these issues. There was a tendency to go too slowly because of over-sensitivity to differences. In the literature review we saw that authors cautioned against this, as a slow implementation can lead to regressive behaviour; the longer the duration of a stressful event, the higher the degree of stress that will be experienced. It is thus crucial to break the change process down into identifiable steps or phases and to limit the time of implementation. There could have been an improvement in ring fencing critical systems and procedures and to allow time for meetings, planning and preparation. There were frustrations at the management level at having insufficient skills to deal with these particular issues, and lack of institutional support in providing such skills. Institutional support in the form of counselling ideally should be available to all employees, and managers should receive training in assisting staff through the emotional wave of change.

The story is not all bleak, however! Milestones reached and successes achieved were celebrated, and there were many such instances. Many staff had the opportunity to extend themselves and learn from the change process. There was significant personal learning that occurred, and no one came out of the process untouched. It was evident that learning occurred at many different levels.

Four years on from the gazetted date of the merger, there is still considerable work to be done with staff: in encouraging changed mindsets, new ways of thinking and most importantly, in building trust and a sense of belonging to a new family.

\section{Conclusion}

Systems, processes and people all need attention during a change process. Systems and processes are often easier to deal with as they are more tangible. It is, however, the 'soft', untangible issues relating to employees that demand the attention and planning of managers if change is to be truly successful. Managers thus play a vital role, and yet are often unsupported in their roles while having to support, encourage and motivate staff during the change process. It is hoped that some of the elements highlighted from the DUT library merger can be useful to others undergoing similar change experiences.

\section{References}

Beckhard, R. and Pritchard, W. 1992. Changing the essence: the art of creating and leading fundamental change in organizations. San Francisco: Jossey-Bass.

Bridges, W. 199I. Managing transitions: making the most of change. Reading, Mass.: Perseus Books.

Bruyns, H.J. 200I. A model for managing large-scale change: a higher education perspective. South African Journal of Higher Education, I5(2): |14-21.

Clarke, L. 1994. The essence of change. New York: Prentice Hall.

Coffey, J., Garrow, V. and Holbeche, L. 2002. Reaping the benefits of mergers and acquisitions: in search of the golden fleece. Oxford: Butterworth Heinemann.

Costello, S. J. 1994. Managing change in the workplace. Boston: Irwin Professional Publishers.

Devine, M. 1997. Mergers and acquisitions: the Roffey Park mergers and acquisitions checklist: a guide to effective people management during a merger or acquisition. Horsham: Roffey Park Management Institute.

Devine, M. and Hirsh, W. 1998. Mergers and acquisitions: getting the people bit right. Horsham: Roffey Park Management Institute. 
Duck, J.D. 200I. The change monster: the human forces that fuel or foil corporate transformation and change. New York: Three Rivers Press.

Garrow, V. 2003. The merger of M L Sultan and Technikon Natal libraries: the first year of the Durban Institute of Technology Library 2002-2003. Unpublished report.

Garrow, V., Devine, M., Hirsh, W. and Holbeche, L. 2000. Strategic alliances: getting the people bit right. Horsham: Roffey Park Institute.

Jayaram, V. 2003. The merger process between libraries of ML Sultan and Technikon Natal: reflections of a practitioner. South African Journal of Libraries and Information Science, 69(I):84-9I.

Jerome, P.J. 1994. Re-creating teams during transitions: a practical guide to optimizing team performance during changing times. Irvine, CA: Richard Chang Assoc.

KPMG Consulting. 2002. Change management training workbook. Unpublished document.

Macomoza, S. 2002. Press statement on the Report of the National Working Group on the restructuring of the higher education system. Cape Town, Monday II February. [Online] http://education.pwv.gov.za/DOE_Sites/Higher_Education/media/ saki\%20macozoma.htm. Accessed 12 February 2002.

Muller, Nicole J. 2003. The management of change: guiding staff through transition within the framework of a merger of libraries from two different Higher Education institutions. Unpublished thesis. University of Natal, Pietermaritzburg.

Pritchett, P., Robinson, D. and Clarkson, R. 1997 rev. ed. After the merger: the authoritative guide for integration success. New York: McGraw-Hill.

Robbins, S.P. 1991. Organizational behavior: concepts, controversies and applications. Englewood Cliffs, NJ.: Prentice-Hall.

Senior, B. 1997. Organisational change. London: Prentice Hall.

Snowden, D. 2002. Just-in-time knowledge management, part I. Knowledge Management Review, 5(5): I4-I7.

Spekman, R. E., Isabella, L.A., MacAvoy, T. and Forbes, T. 1996. Creating strategic alliances which endure. Long Range Planning, 29(3):346-357.

Strickland, A.J. and Thompson, A.A. 1998. Cases in strategic management. Boston, Mass.: Irwin/McGraw-Hill. 